\title{
STI policy and governance in Sub-Saharan Africa: Fostering actors' interactions in research and innovation
}

Industry and Higher Education

$$
1-16
$$

(C) The Author(s) 2021

(c) (i)

Article reuse guidelines: sagepub.com/journals-permissions DOI: $10.1177 / 09504222211026218$ journals.sagepub.com/home/ihe

\author{
Remy Twiringiyimana $\mathbb{1}$ \\ University College London, UK \\ Chux Daniels \\ University of Sussex Business School, UK \\ Joanna Chataway \\ University College London, UK
}

\begin{abstract}
This study investigates science, technology, and innovation (STI) policy and governance in relation to research and innovation (R\&l) ecosystems in Sub-Saharan Africa (SSA). To understand the implications of STI policy and governance on R\&l, the authors focus on university, industry and government actors; using the Triple Helix and National Systems of Innovation approaches as analytical frameworks to guide the study. The authors identify a range of factors hindering R\&I actors' interactions, including gaps in STI governance responsibilities and accountabilities, policymaking and structural transitions, R\&I management capacity and capability gaps. Based on the findings, they propose changes to policymaking and the governance of R\&I in SSA, in addition to advancing innovative approaches such as 'resource circulation' in the context of knowledge, research and science infrastructure scarcity. The findings provide fresh insights into STI policy and governance frameworks, fostering actors' interactions and supporting performance improvements in research, science and innovation systems across Africa.
\end{abstract}

\section{Keywords}

Research and innovation, STI policy and governance, Sub-Saharan Africa, university-government-industry interactions

Science, technology and innovation (STI) play a central role in national, regional and global social and economic development. This role has been more explicitly acknowledged since the second half of the 20th century. During this period, economic growth has become more contingent on knowledge-driven innovation and linkages among ecosystem actors - governments (policy actors), science/ knowledge producers (universities, research and development institutions) and industry - have therefore become imperative (Crow and Dabars, 2015; Galvao et al., 2019). In Sub-Saharan Africa (SSA), however, various research findings and scholarly endeavours continue to point to weaknesses among these ecosystem actors comprising policy, science, research and innovation as one of the reasons for the region's inability to fully exploit the gains from STI (Daniels et al., 2021; Kruss and Visser, 2017).
In an effort to follow the pace of high-income countries and more effectively harness STI for development, countries in the global South, including low- and middle-income countries in SSA, have, to a large extent, had to embed STI in their national social and economic development policies, visions and strategies. For instance, the majority of countries in SSA have developed and adopted or reviewed their national STI policies in the last few decades (AU, 2019; Chataway et al., 2019; Daniels et al., 2017). This reflects in part a strategy to become knowledge-based economies, as

\section{Corresponding author:}

Remy Twiringiyimana, Science, Technology, Engineering and Public Policy (STEaPP), University College London, Shropshire House (4th Floor), II20 Capper Street, London WCIE 6JA, UK.

Email: remy.twiringiyimana.18@ucl.ac.uk 
articulated in the African Union's Science Technology and Innovation Strategy for Africa (STISA-2024 - AU, 2014), driven by STI, so that they are prepared to address and respond to the social, environmental and economic challenges of the 21st century (Daniels et al., 2020; Mazzucato, 2018; Schot and Steinmueller, 2018).

However, in addition to weaknesses in interactions among STI ecosystem actors, evidence shows that STI policies and regulations in SSA, which to a large extent are formulated with the frameworks of the Triple Helix (TH) of universities, industry, and government (U-I-G) (Etzkowitz, 1996; Ranga and Etzkowitz, 2013) and National Systems of Innovation (NSI) (Freeman, 1987; Lundvall, 1992; Nelson, 1993), do not necessarily correlate with the context (Arocena et al., 2017; Diyamett et al., 2019). Hence, it becomes problematic to study the status of science, technology, research and innovation, and to measure innovation performance in these countries (Albuquerque et al., 2015; Yongabo, 2021). Innovations happen on various scales and in various forms relevant to the local context (Chataway et al., 2014). There is therefore a need to investigate and better understand STI policies and their relationship with research and innovation $(R \& I)$ and the governance of R\&I in SSA countries.

We argue that advancing knowledge and understanding of R\&I governance will have implications for STI policy and the ability of SSA countries to exploit STI more adequately for development purposes. We further contend that, because TH and NSI frameworks evolve within the contexts in which they are applied, it is important to use these concepts to guide policy research rather than applying them as fixed constructs to be implemented in innovative policies and policy processes during policymaking. We take the position that, as conceptual frameworks, TH and NSI should be used to help countries and regions shape their STI policies, governance and regulatory frameworks, allowing room for reconceptualising innovation and policies where applicable (Daniels, 2017; Daniels et al., 2017).

As frameworks to guide innovation policy and research, TH and NSI emphasise the importance of strong links, interactions and collaboration among actors - two of which are universities (or academia) and industry. As noted above, policy and scholarly discourse concerning university-industry collaboration have consistently found that inadequate cooperation among these actors plays a major role in hindering the performance of the NSI, especially in Africa and other low- and middle-income countries (Daniels et al., 2020, 2021; Kruss and Visser, 2017; Yongabo, 2021). The extent to which STI policy is governed, and the manner in which structural settings are established, may facilitate or hinder the performance of the NSI. Against this backdrop, we set out the objectives and associated questions for our study, followed by a brief outline of the paper.

\section{Research objectives and questions}

In this study, we focus on one main research question and two subsidiary questions:

- In what ways can the theoretical foundations underpinning TH and NSI help address the challenge of weak interactions among R\&I actors in SSA?

- 1(a) Could gaps in STI policy, capabilities, R\&I governance and structural issues be responsible for persistent weak interactions among R\&I actors and, if so, to what extent?

- 1(b) How can TH and NSI contribute to rethinking STI policy in ways that will help strengthen interactions among R\&I systems in SSA?

Based on these questions, our three objectives were to:

- investigate how the theoretical foundations underpinning TH and NSI could help address the challenges of weak interactions among R\&I actors in SSA;

- interrogate possible issues that have instigated the persistent weak interactions that exist among R\&I actors in SSA; and

- discuss the role of TH and NSI in STI policymaking to strengthen interactions among R\&I systems in SSA.

In respect of the above, we point out that research question 1 focuses on scientific contributions, while subsidiary questions $1 \mathrm{a}$ and $1 \mathrm{~b}$ relate to the various pertinent policy contributions.

The remainder of this paper is structured as follows. The next section, 'Materials and methods', reviews the key theoretical concepts and provides the research methodology and analytical framework of the study. The 'Findings and discussion' section then focuses on country analysis, and we examine Rwanda and South Africa as illustrative case studies in STI policy, governance and actors' interactions in SSA. The final section provides our conclusions and our recommendations for further research.

\section{Materials and methods: Theoretical concepts, methodology and analytical framework}

\section{TH and NSI as theoretical and conceptual frameworks for STI policy}

TH: From statist to balanced model. TH, like NSI, is grounded in systems theory which comprises elements and interaction between elements and their functions (Egbetokun et al., 2017; Ranga and Etzkowitz, 2013). The first evolution of innovation governance - argued by numerous scholars to have been dominant since the 1960s when 
Table I. Conceptualisation of TH growth strategy.

\begin{tabular}{ll}
\hline Factors & Knowledge-based growth indicators \\
\hline I. Human capital & I. A critical corpus of scientists and engineers linked through social networks \\
(networks often linking researchers from among U-I-G laboratories within the & $\begin{array}{l}\text { region). } \\
\text { 2. Existence of research groups in fields of potential commercial expansion. } \\
\text { 3. A pool of scientists and engineers intent on forming their own firms (faculty } \\
\text { members, graduate students, or scientists and engineers from government or } \\
\text { industrial laboratories/research centres). }\end{array}$
\end{tabular}

2. Material resources and inputs

I. Availability of seed capital from governmental or private resources.

2. Inexpensive and appropriate space for new firms in underutilised industrial, government or university premises.

3. Equipment, ranging from the Internet of Things (loT), machine learning (data science and artificial intelligence) systems to biotechnology models.

3. Factors contributing to a favourable regional innovation environment

I. Opportunities for scientists and engineers to acquire business skills or gain access to skilled personnel (a postgraduate school of business offering consulting services or entrepreneurship courses in which students develop business plans).

2. University policies designed to: (a) encourage faculty members and students to interact with industry; (b) award academic credits to promote and attract degree students in this field; (c) provide clear guidelines delineating appropriate activities.

3. Applied research institutes, centres and incubator facilities to assist firms incurring development problems and to provide mediating connections between academic scientists and industrial field engineers.

4. A residential community with cultural, scenic and/or recreational resources that can attract and retain a talented, potentially highly mobile population as a result of its skill set.

Source: Adapted from Etzkowitz (1996).

governments focused on funding basic research and scientific discoveries at universities - placed emphasis on the application of research for innovation and commercial use in industry. This innovation model is widely associated with the famous work by Vannevar Bush, 'Science: The endless frontier' (Bush, 1945). In this paper, Bush argued that, for universities to engage in $R \& D$, the US Government would need to stimulate innovation by increasing research funding while respecting the autonomy of universities (Diyamett et al., 2019; Meusburger et al., 2018: 294). The purpose was to address market failure when industry was incapable of or unwilling to invest in basic research (Schot and Steinmueller, 2018). From the 1960s to the 1980s, universities and industry were government-controlled and regulated (Datta et al., 2019), a situation denoted as a 'statist model of TH' (Ranga and Etzkowitz, 2013). This model still prevails, particularly in SSA where basic research and universities are, in most cases, largely funded by governments.

The 1980s and 1990s were dominated by 'corporatebased competitiveness', with the success of large R\&Dperforming firms contingent on both their technological and marketing capabilities (Diyamett et al., 2019). According to Datta et al. (2019), this was the second revolutionary innovative governance model, named the 'laissez-faire' model of TH. In this model, TH actors were operating in accordance with their own developmental strategy, with little or no interconnection between one another and reduced governmental influence on engagement between universities and industries.

$\mathrm{TH}$ frameworks suggest that universities and other research institutions responsible for knowledge production assume a central role, while governments' main responsibilities are to formulate innovation and industrial policies to facilitate interaction between knowledge producers and industry (Galvao et al., 2019). When the roles of these TH actors complement one another in an overlapping and substitutional manner, TH is said to be 'balanced' (Ranga and Etzkowitz, 2013). In articulating the process of formation and growth of TH, Etzkowitz (1996) stressed that governments should take on a role of an entrepreneurial state. This means that, in addition to putting in place innovation and industrial policies that facilitate interactions between universities and industry, governments strategically provide inter alia infrastructural facilities (establishing science and technology research and innovation agencies and scientific development establishments) and seed funding to drive innovations by university-generated spin-off organisations, which later become 'knowledge-based firms'. This governmental position is in contrast to narratives by some scholars, which tend simplistically to stress that the prime 
function of government in the context of TH-stimulated U$\mathrm{I}-\mathrm{G}$ innovation is to establish policies and regulations (Crow and Dabars, 2015; Galvao et al., 2019). Table 1 encapsulates what are, according to Etzkowitz (1996), the main, although not the only, factors for the expansion of $\mathrm{TH}$ as a 'knowledge-based growth strategy'.

Despite existing resource challenges in SSA, the above arguments suggest that governments should supply adequate means to ensure a functional, effective TH of U-I$\mathrm{G}$ within a given geographical setting. The extent to which SSA universities are supported by government and other actors and stakeholders to deliver their knowledge production mandates in turn partly determines the scope and progress of TH and NSI ecosystems.

From $\mathrm{TH}$ to Quadruple Helix. The adaptation of TH to various social, technical, economic and political contexts has generated various versions of the model over the last two decades. In addition, according to Galvao et al. (2019), the Quadruple Helix (QuadH) models have added new actors such as civil society, media-based and culture-based organisations (Carayannis and Campbell, 2009), green sustainable resources (Gouvea et al., 2013) and 'smart cities' to TH's U-I-G scope.

Under the QuadH model, innovation is an outcome of stimulated interactions among actors in diverse scientific and technological spheres, where knowledge is produced, utilised and renewed by the public sector (government), academia (universities), the private sector (industry) and civil society (non-governmental organisations). The process is catalysed by the combination of top-down policy processes which empower bottom-up entrepreneurship. This complex mode of knowledge production leads to what Carayannis and Campbell (2009) refer to as a 21st century 'Mode 3 innovation ecosystem', 1 in which co-creation and co-evolution of all actors are imperative to ensure sustainable social and economic development. Carayannis and Campbell (2009) go on to suggest that, in the QuadH approach, funding mechanisms for research target socially relevant innovations alongside others focused on economic gain. An important point to note is that, as with TH, universities - and more broadly the R\&I systems which constitute the main focus of this study - remain central to the QuadH approach.

From QuadH to Quintuple Helix. In addition to civil society, the natural environment has been added to $\mathrm{TH}$, increasing it to a Quintuple Helix (QuintH) model of innovation (Baccarne et al., 2016; Galvao et al., 2019). According to Baccarne et al. (2016), the QuintH model of innovation encompasses five interconnected social subsystems, namely: (i) university systems for knowledge generation and dissemination; (ii) industrial systems generating and controlling financial capital; (iii) government or political systems with political, regulatory and legislative capital; (iv) civil society, comprising non-governmental organisations which have social capital to safeguard and engage in promoting and upholding the cultural, social and contextual values of society; and (v) the natural environment encompassing natural capital elements such as 'natural resources, climate, air quality and geological stability' (Baccarne et al., 2016). Moreover, the QuintH model uses Mode 3 knowledge production as does the QuadH, in addition to which the former incorporates the natural environment dimension into the narrative.

\section{TH and NSI: Unpacking the relationship}

Effective connectedness within the innovative TH of U-I-G is a prime determinant of a functional NSI (Carayannis and Campbell, 2009; Schot and Steinmueller, 2018). According to the 'systems theory' literature, both TH and NSI are structured according to a systems perspective, the system's performance being contingent on how it is constructed and how actors interact within the innovation process (Datta et al., 2019). Scholars have used TH as one of the conceptual tools to study NSI (Yongabo and Göransson, 2020). Although TH frameworks are chronologically grouped into three categories (statist, laissez-faire and balance), the implementation of these frameworks depends largely on countries' or regions' innovation policy and practice (Daniels, 2017; Ranga and Etzkowitz, 2013). For the purposes of this analysis, however, the use of ' $\mathrm{TH}$ ' in the following section denotes the balanced model unless otherwise stated.

From a systems theory perspective, both TH and NSI can to some extent be equally considered as scientific and innovation policy conceptual frameworks. For instance, Datta et al. (2019) view TH as a system and not a model. In their conceptual analysis of the two systems, they suggest that TH and NSI share similarities when it comes to their structural composition of actors (U-I-G), policies and regulatory instruments facilitating interaction among actors. In unpacking the relationships between TH and NSI further, we note that, although both frameworks are related in terms of their usefulness in understanding R\&I and informing STI policies, they also differ in some respects, as explained next.

According to Datta et al. (2019), the major difference between TH and NSI is that the university is a central actor for the former while the firm is a main actor for the latter. While the role of universities remains essential in NSI (Datta et al., 2019), it is mainly concerned with knowledge generation, educating and producing (well-accomplished) graduates with the required skills and capabilities to work in firms and other organisations within the national economic system, and to conduct research in their laboratories (Lundvall, 2010). Therefore, according to Datta et al. (2019), the contribution of the university (or research) system to the innovation process is greater in $\mathrm{TH}$ than it is in 
NSI. We shall revisit this point in subsequent sections when discussing the role of TH in facilitating university interactions with other actors, taking Rwanda and South Africa as case examples. In the section below, we discuss the rationale for selecting Rwanda and South Africa as examples on the basis of contextual features underpinning STI policy and governance in the two countries. In the same section, we also present the methodology and analytical framework supporting our investigation in this study.

\section{Country selection, methodology, and analytical framework \\ Contextualising STI policy and governance in SSA: Rationale for country selection}

We start by acknowledging the diversity across Africa, a continent of over 50 countries, with SSA accounting for the majority of them. Although this point is beyond the scope of this paper, it is widely accepted that both Rwanda and South Africa consider 1994 as their year of 're-birth'. The former was entering into the postgenocide era, while the latter was transitioning from decades of Apartheid to democracy. To support their transformation objectives, both countries placed STI at the centre of their respective national development agendas, although evidence shows that, historically, scientific and technological capabilities in South Africa have been more advanced than in other African countries, including Rwanda. For instance, recent studies have suggested that South Africa is by far the most research-intensive SSA country, owning $44 \%$ of the continent's total publications (Zavale and Langa, 2018).

According to the African Innovation Outlook III and the Rwanda R\&D survey report, South Africa's higher education expenditure on R\&D (HERD) is $0.2 \%$ of GDP, with Rwanda registering 0.08\% (AU, 2019: 14). This implies that South Africa's higher education system is 2.5 times more R\&D-intensive than that of Rwanda. In addition, Rwanda's and South Africa's gross domestic expenditure on R\&D (GERD) as a percentage of GDP amounts to 0.82 and 0.66 respectively (AU, 2019: 10; GoR, 2020a: 35). Although this remains below AU member states' commitment to $1 \%$ for 'maximum ownership and responsibility of their developmental path' as stated in STISA-2024 (AU, 2014: 41), these GERD statistics of $0.82 \%$ and $0.66 \%$ are high by comparison to other African countries. For Rwanda, the current $0.66 \%$ R\&D share of GDP is higher than the $0.5 \%$ which was set in the 2005 STI Policy (Hanlin and Tigabu, 2017: 32). Rwanda has thus renewed its commitment to meeting the $1 \%$ R\&D share of GDP by 2024 as stated in the newly approved STI Policy (GoR, 2020b: 18).

Given this wide contrast in the maturity of the two countries' scientific and technological statuses, there may be a plethora of factors contributing to this divergence. In line with the aims of this study, we thus focus only on two factors, STI policy and governance of R\&I and issues relating to structures, in order to understand the possible reasons for weak interactions among STI actors and propose possible ways in which TH and NSI may help rethink STI policy and strengthen interactions between R\&I actors. Table 2 summarises Rwanda's and South Africa's respective distinct features validating the basis for selecting these two countries.

Based on the data in Table 2, we selected Rwanda and South Africa because of their concurrently similar yet contrasting R\&D and STI characteristics, which reflect the diversity across the SSA region and the wider African continent. Key observations with respect to similarities and contrasts in R\&I and STI characteristics in Rwanda and South Africa are presented in Table 3.

In the next section, we present the methodology and analytical framework used to guide the investigation of our research questions, with Rwanda and South Africa as case examples. We point out that, although we use Rwanda and South Africa as case countries to provide context, the purpose of the study is not to conduct a comparative analysis of the two countries. It is our aspiration that our answers to the above questions, based on evidence from Rwanda and South Africa, will add to existing knowledge and contribute to the theoretical and conceptual understanding of the role of TH and NSI in fostering interactions among R\&I actors in SSA's STI policy and governance setting - and will consequently contribute to improvements in the performance of R\&I systems in SSA.

\section{Methodology and analytical framework}

The methodology used in this study was based on a review of selected recent journal articles, books and reputable conference papers, as well as reports and policy documents from governments and international organisations. The selection was undertaken using University College London's (UCL's) online library research facility and associated search engines such as Scopus and Research Gate. The literature selection was based on publications with keywords such as: 'Triple Helix' and its derivatives, 'National Systems of Innovation', 'science and technology policy', 'innovation policy [frameworks of]', 'Rwanda', 'South Africa' and 'Sub-Saharan Africa'. Zotero software was used for metadata storage, analysis and referencing of all cited research documentation. Although the selected references served the purpose of this study, we are aware that, given the breath of the topic, it is possible that some relevant literature which could have contributed to the analysis and helped to fully respond to our research questions may have been missed. Nevertheless, we are confident that the literature search and coverage were sufficiently representative to provide the basis for a robust analysis that informed our findings 
Table 2. Rwanda and South Africa: Summary of distinctive research and innovation features.

\begin{tabular}{|c|c|c|c|}
\hline Country settings & Rwanda & South Africa & Features \\
\hline Population, total (millions) & 12.30 & 57.78 & Overview and demographic \\
\hline Surface area (sq. km) (thousands) & 26.3 & $1,219.1$ & \\
\hline Poverty rate (\% of population) & 38.2 & $53.2(2010-2015)$ & \\
\hline GDP per capita (current US\$) & $801.65(2019)^{a}$ & $6001.40(2019)^{b^{\prime}}$ & \\
\hline $\begin{array}{l}\text { Mobile phone subscriptions (per } \\
\quad 100 \text { people) }\end{array}$ & 78.9 & 159.9 & \\
\hline $\begin{array}{l}\text { Individuals using Internet (\% of } \\
\text { population) }\end{array}$ & 21.8 & $56.2(2017)$ & \\
\hline Higher education institutions & 30 & 149 & Higher education, research \\
\hline Public higher education institutions & 1 & $26(2016)$ & and innovation \\
\hline $\begin{array}{l}\text { Total (public and private) higher } \\
\text { education institutions per I million } \\
\text { inhabitants }\end{array}$ & $2.4^{*}$ & $2.5^{*}$ & ecosystem \\
\hline $\begin{array}{l}\text { Academic staff with } \mathrm{PhD}(\% \text { of all } \\
\text { academics, aka university teaching } \\
\text { staff) }\end{array}$ & 20.3 & $43(2014)^{d}$ & \\
\hline Annual HEls doctoral $(\mathrm{PhD})$ graduates & $6(2016 / 2017)^{c}$ & $3164(2016)$ & \\
\hline R\&D expenditure (as \% of GDP) & 0.66 & $0.82(2016)$ & \\
\hline $\begin{array}{l}\text { Higher education expenditure on R\&D } \\
\text { (HERD) (as \% of GDP) }\end{array}$ & 0.08 & 0.2 & \\
\hline Innovation rate $\mathrm{e}^{\mathrm{e}}$ & - & $65.4 \%(2014)$ & \\
\hline STI policy & $\begin{array}{l}\text { National STI Policy (2020) } \\
\text { Based on TH framework }\end{array}$ & $\begin{array}{l}\text { STI White Paper (2019) } \\
\text { Based on QuadH framework }\end{array}$ & $\begin{array}{l}\text { STI policy and governance } \\
\text { ecosystems }\end{array}$ \\
\hline $\begin{array}{l}\text { Governance: institutional settings and } \\
\text { structure }\end{array}$ & $\begin{array}{l}\text { No S\&T Ministry } \\
\text { A single agency }\left(\mathrm{NCST}^{\mathrm{g}}\right) \\
\text { coordinates R\&l and } \\
\text { funding }\end{array}$ & $\begin{array}{l}\text { ST\&HE } f^{f} \text { ministry } \\
\text { Multiple agencies (DSI, NRF } \\
\text { etc.) coordinate R\&I and } \\
\text { funding }\end{array}$ & \\
\hline
\end{tabular}

Source: AUDA-NEPAD (2014); GoSA (2016); British Council (2018); World Bank (WB, 2018a, 20I8b); AU (2019); GoR (2019b).

Note: *Authors' computation. a https://data.worldbank.org/indicator/NY.GDP.PCAP.CD?locations=RW (accessed 24 November 2020); bhttps://data. worldbank.org/indicator/NY.GDP.PCAP.CD?locations=ZA (accessed 24 November 2020); ${ }^{\text {R }}$ wanda's Education Sector Statistics, https://www. mineduc.gov.rw/fileadmin/user_upload/Mineduc/Publications/STATISTICS_PDF_and_EXCEL_SHEETS/I_Rwanda_Education_Statistics2019.pdf (accessed 24 November 2020); ${ }^{-}$Research and PhD Capacities in SSA: South Africa, https://www.britishcouncil.org/sites/default/files/h233_02_south_

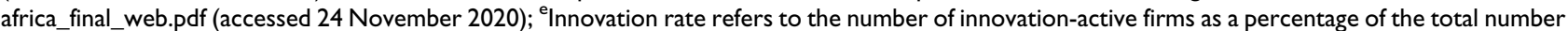
of firms (AUDA-NEPAD, p. 124), https://www.nepad.org/publication/african-innovation-outlook-ii (accessed 25 November 2020); fScience and Technology, and Higher Education Ministry, South Africa; ${ }^{8}$ National Council for Science and Technology, Rwanda; hDepartment of Science and Innovation and National Research Foundation, South Africa.

and conclusions. The country and data analysis and associated discussions that follow were informed by $\mathrm{TH}$ and NSI frameworks.

\section{Findings and discussion: STI policy, governance and actors' interactions}

The analyses in this section focus on the aforementioned experience of STI policy and governance of the two case countries (Rwanda and South Africa), concentrating on the three research questions, and interrogating the data through the TH and NSI lenses. We explore some of the reasons why, despite progress discussed in preceding sections - in STI policy, governance and actors' interactions in Rwanda and South Africa - the challenge of weak interactions among R\&I actors and the broader STI ecosystem persists. For each country, the analysis starts by methodically dismantling the structure in relation to the governance of STI policy. Thereafter, the research questions are addressed, which task provides the basis for the conclusions presented in the final section.

\section{Rwanda: STI policy and governance of research and innovation}

The development trajectory of Rwanda is based on its ambitious Vision 2050 as stated in its National Transformation Strategy (NST1). Rwanda aspires to achieve upper-middle-income status by 2035 and to be rated as a higher-income country by 2050 , when all Rwandans would be enjoying high-quality living standards, with opportunities to participate in a productive economy. The Vision targets four broad priorities - 'High quality of life and standard of living; Transformation for prosperity 
Table 3. Rwanda and South Africa: Key observations of similarities and contrasts in R\&I and STI characteristics.

\begin{tabular}{|c|c|c|}
\hline R\&D and STI characteristics & Similarity & Contrast \\
\hline $\begin{array}{l}\text { R\&D expenditure as \% of } \\
\text { GDP and GDP per capita }\end{array}$ & $\begin{array}{l}\text { R\&D expenditure as \% of GDP of } 0.66 \text { and } 0.82 \text {, } \\
\text { respectively, for Rwanda and South Africa } \\
\text { exceeds the SSA average }(0.5) \text {. }\end{array}$ & $\begin{array}{l}\text { South Africa's GDP per capita is over seven times as } \\
\text { high as that of Rwanda, which partly demonstrates } \\
\text { Rwanda's drastic effort in investing in R\&D in } \\
\text { relation to its lower economic performance. }\end{array}$ \\
\hline $\begin{array}{l}\text { Organisational and } \\
\text { institutional settings } \\
\text { for human capital } \\
\text { development }\end{array}$ & $\begin{array}{l}2.4 \text { and } 2.5 \text { higher education institutions per } \\
\text { million inhabitants in Rwanda and South Africa, } \\
\text { respectively. }\end{array}$ & $\begin{array}{l}\text { Universities in South Africa produce significantly } \\
\text { more doctoral (PhD) graduates than Rwanda, the } \\
\text { ratio being about } 527 \% \text {, which partly explains the } \\
\text { divergence in scientific and technological } \\
\text { capabilities in the two countries. The number of } \\
\text { doctoral academic staff (PhD holders) in South } \\
\text { Africa is over twice that in Rwanda, which is } \\
\text { reflected in a similar discrepancy between the two } \\
\text { nations in respect of R\&D intensity in higher } \\
\text { education. }\end{array}$ \\
\hline $\mathrm{HE}$ and R\&I & $\begin{array}{l}\text { In both countries the higher education sectors } \\
\text { (more generally R\&l) are dominated by public } \\
\text { universities. }\end{array}$ & $\begin{array}{l}\text { Rwanda has only one public research university - the } \\
\text { University of Rwanda (UR), }{ }^{\text {a }} \text { while South Africa } \\
\text { boasts } 26 \text { public higher education institutions } \\
\text { operating independently from one another. }\end{array}$ \\
\hline STI policy & $\begin{array}{l}\text { The two countries have relatively new STI } \\
\text { policies. }\end{array}$ & $\begin{array}{l}\text { Rwanda's STI policy (2019) was conceptually } \\
\text { designed through the lens of TH while South } \\
\text { Africa's STI White Paper (2019) was designed on } \\
\text { the basis of a QuadH framework. This partly } \\
\text { implies the divergence in actors' engagement in } \\
\text { policymaking and governance (this is discussed } \\
\text { further in this study). }\end{array}$ \\
\hline STI governance & - & $\begin{array}{l}\text { With no dedicated national S\&T Ministry, Rwanda's } \\
\text { R\&I programmes, STI policy implementation and } \\
\text { other STI-related activities are coordinated and } \\
\text { funded through a single semi-autonomous public } \\
\text { entity (NCST). In South Africa's context, the DSI } \\
\text { under the ST\&HE Ministry is responsible for the } \\
\text { design of STI policy. It also oversees the } \\
\text { implementation and coordination of STI policy. In } \\
\text { addition, DSI oversees R\&I coordination and/or } \\
\text { funding in collaboration with multiple agencies. }\end{array}$ \\
\hline
\end{tabular}

Note: a UR was formed in 2013 as a merger of seven former public universities and higher education institutes in Rwanda.

(development of high-value and competitive jobs and sectors); Development of modern infrastructure and productive livelihood; and positive contribution to international peace and prosperity' (GoR, 2017: 9; WB, 2018c: 8) - with information technology (IT) and STI being essential drivers to attain development goals in priority areas (GoR, 2017: 66; WB, 2018c: 9).

Could gaps in STI policy, governance of R\&I and issues of structures be responsible for the persistently weak interactions, and, if so, to what extent? Although Rwanda has not had a specific Ministry for Science and Technology (S\&T) for over a decade, STI has remained strategically positioned within her governance circle. Following approval of the 2005 STI policy, responsibilities of the then-Ministry in the President's office in charge of science, technology and scientific research were moved to the Ministry of Education under the Department of
Science, Technology, and Research (DSTR) formed in 2009 (Lemarchand and Tash, 2015: 131). In addition to its other responsibilities for national research coordination and regulation as well as R\&I funding, DSTR's core role was to oversee the implementation of the national STI policy.

In 2012, the coordination of national STI policy was discharged from the Ministry of Education as a result of the creation of the National Council for Science and Technology (NCST) (UNESCO, 2015: 525), followed by the downsizing and transforming of DSTR into a smaller and specialised unit for science, technology, research and innovation in education. Nevertheless, given the core role of Rwanda's education system for national STI human capital development, the Minister of Education has hitherto remained legally mandated to co-chair the governing council of NCST. As a semi-autonomous public- 
sector agency, NCST was initially located in the Prime Minister's office as a think-tank and STI advisory body for all priority sectors of the national economy.

In 2017 NCST was promoted to the President's office with additional responsibilities for R\&I funding. The most recent change in STI governance instigated by the Government of Rwanda (GoR) was the creation of the Ministry of Information and Communications Technology (ICT) and Innovation in 2019, with the core mandate to provide policy orientation for and coordination of all ICT and innovation policies across all economic sectors (GoR, 2019a). This combination of ICT and innovation at ministerial level partly demonstrates Rwanda's faith in ICTs as innovation drivers to underpin national social and economic development. The aims of this study therefore make it essential to assess Rwanda's higher education structure as a research institution system.

Rwanda's higher education structure is a complex system characterised by three distinct models: public, private and public-private partnership; universities and other further education institutions are further classified under local and foreign institutions. The typology of these universities and other (public and private alike) further education institutions is distinctly based on whether they provide (research-oriented) general education, or technical and vocational education and training (TVET). For instance, as alluded to in previous sections, the University of Rwanda (UR) - Rwanda's only public research university - was founded in 2013 as a result of the merger of seven former state universities and institutes, with campuses across all five of the country's provinces. In a similar vein, the Rwanda Polytechnic (RP) was established in 2017 as an umbrella institution incorporating eight merged, integrated polytechnic regional centres (IPRCs) across all provinces and other Rwandan sub-sectors (urban, suburban and rural). Exploring possible conceptual frameworks - such as that proposed in Table 1 - that could foster higher levels of actor interactions amid this complex, dynamic and fastmoving STI governance within a 'nascent' NIS is the objective of this study.

The first evaluation of Rwanda's STI policy, conducted in 2013, focused on four policy pillars: knowledge acquisition, knowledge creation, knowledge transfer and innovation culture (Murenzi and Hughes, 2006; Yongabo, 2021). The recommendations from that evaluation with respect to policy design, its implementation and STI governance included the need to: (a) streamline policy priorities to improve coherence; (b) develop policy implementation strategy, including community-based STI programmes for community engagement; and (c) cultivate innovation system functions among key actors (Farley et al., 2013: 9-10).

The second review of Rwanda's STI policy, performed in 2018, stressed that 'STI policy needed to be formulated and implemented using a conceptual framework of NSI' (UNCTAD, 2017: 20). The recommendation was partly based on identified 'insufficient levels of interaction' between government, academia and industry (UNCTAD, 2017: 65), and specifically among actors in the ICT sector (UNCTAD, 2017: 55-56). In addition, Yongabo and Göransson (2020) suggested that weak interactions among actors had partly contributed to a hampering of cocreation and knowledge flow for innovation in Rwanda (Yongabo and Göransson, 2020). Other gaps in the underpinning of Rwanda's STI policy, governance and R\&I interactions are discussed below:

i. Although STI has maintained a central and strategic role in Rwanda's development agenda, 'STI sparked with high visibility' in the period 20062009 when there was a dedicated Ministry for Science, Technology, and Scientific Research (Farley et al., 2013: 15). The length of time it took for the 2005 STI policy to be revised and approved may have been associated with the absence of a Ministry with a core mandate to oversee STI policy. The initial transitional stages of the STI policy governance mandate issued by the Ministry of Education to NCST undoubtedly impacted detrimentally on R\&I interactions. For instance, the small-scale funding programmes that had stimulated academia-industry interactions such as the Knowledge Transfer Partnership programme (KTP) and the Rwanda Innovation Endowment Fund (RIEF) (Farley et al., 2013: 37), previously run by the Ministry of Education, were discontinued. This was partly because, in its early days of existence, NCST did not have an R\&I funding mandate, as discussed earlier. A dedicated ministry to govern, coordinate and champion STI policy in ways that would help guarantee a sustained focus on R\&I would have been, and remains, essential to strengthen interactions among actors.

ii. Although the move of the STI policy mandate from the then-Ministry within the President's office in charge of science, technology and scientific research to the Ministry of Education in 2009 did facilitate the capacity for wider science and technology development, this shift led to a structural issue. For instance, for nearly half a decade of its existence, the then-DSTR (a department under the Ministry of Education) experienced structural hardship in influencing STI and research policy and interventions in other ministries and agencies beyond the education sector. Moreover, R\&I funding fell vulnerable to conflicting priorities and imperatives in the education sector.

This brings us to the points encapsulated in our two subsidiary research questions. First, why has the challenge of weak interactions among STI (in particular, R\&I) 
organisations in Rwanda persisted despite the various structural and STI governance reforms described above? Could, for example, gaps in capability be responsible for the weaknesses in the R\&I/STI ecosystems? Consequently, and secondly, in what ways could the theoretical foundations underpinning TH and NSI help to address this challenge of weak interactions among R\&I actors in Rwanda?

There are indications that, alongside these questions, policy changes are being advanced to promote interactions among Rwanda's R\&I system actors. For example, the UNCTAD review of Rwanda's STI policy ecosystem suggests that, together, elements of interaction between government agencies on the one hand and public-private collaboration for the operationalisation of community processing centres on the other hand are signs of a 'nascent' NSI in the country (UNCTAD, 2017: 34). In addition, in spite of the weak interactions among actors, there is recognition of favourable developments that position Rwanda in the category of an 'emerging NSI' (Yongabo and Göransson, 2020): these include the emergence of organisational and institutional settings that facilitate the creation, flow and use of economically useful knowledge. In the section below, we discuss the role of TH and NSI in addressing the aforementioned gaps.

How can TH and NSI contribute to the rethinking of STI policy in ways that help strengthen the interactions among R\&I systems in Rwanda? In the case of Rwanda, the gaps resulting from the lack of a conceptual framework to guide the earlier version of the national STI policy design and related policy instruments have been partly addressed by the new STI policy, which was developed based on NSI and $\mathrm{TH}$ with the aim of strengthening synergies among the three key actors: academia, government and industry (GoR, 2020b: 6). Since this is a recent development and the STI policy was launched only in June 2020, it is too early to assess its impact on NSI and TH and on interactions among R\&I actors. However, the following are the major transformational factors stemming from $\mathrm{TH}-$ and NSI-based STI policy, governance and structural dynamics, which underpin the response to the aforementioned gaps:

(i) NCST's elevation to the status of highest office and occupation of a position of influence have reduced the structural, governance and research coordination issues. NCST's additional mandate to oversee R\&I funding - with its budgetary autonomy - has given it impetus to negotiate R\&I funds with the government, private sector and other collaborators alike, which has to a large extent facilitated R\&I interactions. For instance, the National Research and Innovation Fund (NRIF) and the Rwanda Innovation Fund (RIF) were launched in 2018. According to the new STI policy, NRIF is tasked with funding STI-based research in strategic areas of the national research agenda, while RIF mainly targets innovators and entrepreneurs from non-R\&D performing SMEs (GoR, 2020b: 8). The setting up of mechanisms to raise awareness and foster capabilities of a wide range of potential beneficiaries of these funds is crucial for stimulating actors' interactions. This not only sets diverse (R\&D-based and nonR\&D-based) directionalities onto innovative pathways for development, but also underpins inclusivity in NSI (Chataway et al., 2014; Daniels et al., 2017).

(ii) In addition to other specialised funds such as the National Climate and Environment Fund (FONERWA) for Rwanda's green growth (Lemarchand and Tash, 2015: 223) and those directly channelled towards government research institutions such as, inter alia, the Rwanda Biomedical Centre (RBC) and Rwanda Agriculture Board (RAB) (GoR, 2020b: 8), the two consolidated funds (NRIF and RIF) ${ }^{2}$ have widely encouraged and improved NCST's interaction with government, academia and industry. For instance, the formation of the national research coordination committee $(\mathrm{RCC})^{3}$ led by NCST with a membership of strategic actors (government and academia) has created a formal network aimed at aligning actors' R\&I goals and establishing directionality for national R\&I funding. Such (formal or informal) networks enable and strengthen horizontal and cross-institutional interactions in R\&I, though it is too soon at present to determine the RCC's impact.

(iii) In this vein, the R\&I grants run by NCST targeting (public-private) academia-industry collaborative projects are not only stimulating and incentivising R\&I interactions between government, academia (public, private and publicprivate partnership universities) and industry but are also instilling a culture of funding $R \& D$ in the private sector. However, despite the availability of consolidated funding, which has facilitated grant application processes and improved interactions between NCST (on the supply side) and academia and industry (on the demand side), the overall output in terms of R\&I remains weak, as reflected in the low innovation intensity, as discussed further below.

(iv) Lastly, the merging of public universities into a single university (UR) and of public technical colleges into the one polytechnic (RP) has helped to improve interactions with government with respect to STI policy and governance. In addition, as state-funded academic organisations, UR and RP are mandated to align their research and 
training programmes with the national development agenda. However, whether or not these mergers have improved interactions in R\&I with industry will require further investigation, as current evidence is scanty. Nonetheless, the limited capacity and capability to manage research is one of the prime detrimental factors limiting R\&I interactions not only with industry but also with other actors. For instance, as discussed previously, and as is clearly illustrated in Table 2, while Rwanda and South Africa have registered nearly equal spending ratios - as percentages of GDP - on R\&D ( $0.66 \%$ and $0.82 \%$, respectively), South Africa's higher education system is 2.5 times more R\&D-intense than that of Rwanda. This disproportionately low R\&D intensity in Rwanda's higher education system - in addition to the wide differences in its numbers of academic researchers with $\mathrm{PhDs}$ and production of $\mathrm{PhD}$ graduates compared to South Africa - explains in part the scanty R\&I capacity and capabilities in Rwanda's higher education sector, with undesirable implications for the performance of the country's NSI (GoR, 2020b: 18). In addition to the aforementioned evidence, recent studies, including the Global Innovation Index (GII 2020), have demonstrated that, in Rwanda, the G in U-I-G became very strong, with $U$ being the weakest and least connected actor in $\mathrm{TH}$, pushing it $(\mathrm{U})$ further into silos (GoR, 2020b; WIPO, 2020; Yongabo, 2021; Yongabo and Göransson, 2020). As a policy priority, promoting R\&I capacity and development capability in (public and private) academia is paramount if Rwanda is to meet its expenditure target of $1 \%$ of GDP on R\&D by 2024 .

\section{South Africa: STI policy and governance on research and innovation}

Could gaps in STI policy, the governance of R\&I and issues of structure be responsible for the persistently weak interaction; and if so, to what extent? As in Rwanda, STI is considered the key driver for South Africa's 'economic growth, job creation, and socio-economic reform', as embodied in the Government of South Africa (GoSA)'s National Development Plan (NDP) of 2012 (GoSA, 2012; see also GoSA, 2019: 3). The support for development innovation is thus recognised at national, provincial and municipal levels. To this end, the relevant infrastructure already in place, such as national science and technology parks which underpin U-I-G collaborations, exemplifies South Africa's commitment to using STI for economic growth as stated by Daniels et al. (2017). Despite noticeable interactions among the main $\mathrm{TH}$ actors, however, policy instruments to support and promote inclusivity ${ }^{4}$ and reduce inequalities while boosting economic growth are either inadequately articulated or underemphasised (Daniels et al., 2017, 2020; Soares and Cassiolato, 2013).

The approval of the revised STI policy of 2019 was subsequently followed by a change in the governance of STI in South Africa. In this change, the Department of Science and Technology (DST) and Ministry of Higher Education and Training were merged in that year to form the Ministry of Higher Education, and S\&T (GoSA, 2019). This decision to merge higher education and STI under one ministry demonstrates the importance of R\&I and S\&Tbased innovation for South Africa's development. It is anticipated that the combination of DST with higher education, and the proposed biennial presidential 'multistakeholder summit' and inter-ministerial structure for STI, in conjunction with strengthened monitoring and an enhanced evaluation system, will stimulate the microcoordination, consolidated planning, prioritisation and policy coherence within NSI (OECD, 2020).

Given its major actor status in both TH and NSI, South Africa's higher education system, its diversity and influence in fostering inclusivity while reducing inequalities, are now discussed.

According to Kruss and Visser (2017), the typology of South Africa's higher education system is characterised by four categories: research universities (ResUs), comprehensive universities (CompUs), Universities of Technology (UoTs), and rural universities (RuralUs). ResUs are further subdivided into two categories: ResU1s - Afrikaansspeaking institutions strategically focusing on entrepreneurship, innovation and partnership with industry; and ResU2s - focusing on academic autonomy and scientific excellence nationally and internationally. CompUs are locally embedded, with more emphasis on teaching and the local relevance of their research and technology production, while the RuralUs' main goal is to teach and contribute to solving local problems.

The formation, mission, structure and strategies of these diversified universities are closely linked to South Africa's historical context. Kruss and Visser (2017) thus argue that industry and government should understand this differentiated nature of universities and take note of their respective values and intellectual and financial imperatives when engaging in partnerships with any of them. That said, 'if linkages with firms are to be strengthened across a system of innovation to promote national development, it is critical to take into account a historically contextualised view from inside the higher education system, and unpack the complex intersection of individual and institutional incentives and barriers' (Kruss and Visser, 2017: 22). The question remains, with the complex higher education system, as to how these linkages can be strengthened in ways that will help achieve the envisaged 'network alignment' and build 'dynamic interactive capabilities' in South Africa's NSI. 
This relates to the third objective (i.e. the second subsidiary research question) explored in this paper.

How can TH and NSI help the rethinking of STI policy in ways that will strengthen interactions among R\&I systems in South Africa? Notwithstanding the foregoing and the relatively stronger structures for TH and NSI with respect to STI policy governance in South Africa compared to Rwanda, the latest analyses of South Africa's NSI reveal that it continues to underperform despite numerous milestones having already been passed since its inception in 1996. The dominant factors underlying this underperformance include: 'Inadequate and non-collaborative means of STI agenda setting for the country, insufficient policy coherence and coordination, weak partnerships between NSI actors - particularly the inadequate involvement of business and civil society, [...] and underfunding' (GoSA, 2019: 12). This underperformance, exemplified by inadequate interactions among U-I-G actors, substantiates arguments by some scholars who suggest that South Africa's status falls into the category of 'immature national innovation systems' (Kruss and Visser, 2017).

In an endeavour to remedy the policy gaps outlined above, the GoSA, through its Department of Science and Innovation (DSI) (formerly the Department of Science and Technology) approved the revised national STI policy in 2019 (that is, the 2019 White Paper on STI). Following notable shifts in the national STI landscape, this new policy proposed an emphasis on 'increasing the focus on inclusivity, transformation, and linkages within the NSI; institutionalising approaches to improve policy coherence, and programme and budget coordination within the NSI; including and supporting civil society and business, with a focus on small and medium-sized enterprises (SMEs) in government planning and funding; supporting local innovation ecosystems, and supporting social and grassroots innovations'. (GoSA, 2019: 98). This White Paper explicitly stressed that South Africa's S\&T policy was based on NSI framing (Cele et al., 2020: 52). It also demonstrated that the policy was a result of collective schools of thought from policymakers, academia, industry and civil society.

The revision of South Africa's STI policy, combined with the implementation ${ }^{5}$ of organisational and structural changes and enhanced capabilities, could potentially address the challenge of weak interactions among actors in NSI. The question remains as to how the implementation strategy for the revised policy will be conceptualised to (a) foster greater interaction among R\&I (but also STI) actors; and (b) harness the improvements in R\&I interactions and optimise the gains from STI to transform South Africa's social and economic development.

The conceptualisation of the revised STI policy (2019 White Paper on STI) through the lenses of NSI and QuadH, with explicit recognition of the sphere of civil society, has a positive implication for STI policy. That is to say, South Africa's STI regime is transitioning towards the inclusivity and sustainability of national development. In addition to involving civil society in consultations to inform STI policy framing, South Africa's revised STI policy proposes to engage civil society in its knowledge and innovation processes - a positive implication for STI governance and R\&I interactions among universities, government, industry and civil society. Nonetheless, the extent of the impact of this STI policy and governance implication on actors' interactions at the macro, meso, and micro levels will be contingent on whether or not South Africa's 10-year implementation strategy for the revised STI policy will also be conceptualised on the basis of the QuadH approach. This will also contribute to determining any changes in performance of the NSI. The remaining factors underpinning STI policy, governance and R\&I interactions are now discussed:

i. The merger of the Ministry of Science and Technology with the Ministry of Higher Education into a single Ministry (GoSA, 2019) has both positive and potentially adverse implications for STI policy and governance. On the one hand, this governance structure facilitates the role of STI policy in streamlining the national development transition towards a knowledge-based society. On the other hand, the extended and onerous mandate of such a Ministry may lead to conflicts of priorities and inefficiencies, particularly when it comes to public funding and collaboration with partners. For instance, experience has shown that, in the case of a single ministry with a combined mandate of S\&T and higher education, the imperatives of funding education and research have prevailed over science and technology. In addition, the propensity for R\&D-based innovation promotion programmes to prevail over non-R\&D-based innovations, also known as knowledge production and co-learning - learning by doing, utilisation and interaction (DUI) - mainly from informal sectors, has brought about the potential for unintended consequences such as increased inequalities (Jacobs et al., 2019). Nevertheless, the goal of bringing STI closer to education and research potentially offers huge gains in addressing weak linkages among R\&I actors and strengthening the necessary interactions. It is therefore expedient that the policy instruments adopted in the implementation of the 2019 White Paper on STI are geared towards this purpose.

ii. The transformation of the former DST into the new Department of Science and Innovation (DSI) will not only enable R\&I interactions but will also expand them to accommodate further actors from non-R\&D innovation sectors and those from social and non-commercial innovation spaces. DSI is mandated to oversee the implementation of the 
national innovation agenda with the goal of addressing three prevailing major challenges: "poverty, unemployment, and inequality' (Cele et al., 2020: 40). With a strengthened monitoring and evaluation system, the proposed biennial presidential 'multi-stakeholder summit' and inter-ministerial structure for STI will spur STI governance via vertical and horizontal micro-coordination, consolidated planning, prioritisation and policy coherence in South Africa's NSI (OECD, 2020). Nonetheless, a recent empirical study showed that continued weak interaction among actors was partly caused by lack of or limited networks, network misalignment and poor dynamic interactive capabilities. That said, in the contemporary era of rapid economic and ecological change, 'network alignment and building dynamic interactive capabilities of multiple actors at macro, meso, and micro levels will be crucial to achieve the policy objectives' (Cele et al., 2020: 52).

iii. Finally, whether the diversified university system enables or impedes R\&I interactions is contingent on numerous factors that merit further empirical investigation. Nonetheless, leaders and managers of universities, government and nongovernmental organisations, as well as private firms, are particularly expected to possess the optimal 'social skills' and 'innovation capabilities' to attain the policy objectives set by their respective organisations through effective engagement with other actors, as contended by Cele et al. (2020: 52, 58).

In the next section, we offer conclusions and recommendations stemming from the analysis of STI policy, governance and structural dynamics, regarding how TH (QuadH in the case of South Africa) and SNI frameworks have partly contributed to promoting R\&I actors' interactions. Moreover, drawing from the experiences of Rwanda and South Africa, and with reference to the theoretical groundings of TH, QuadH and NSI, we attempt to propose a generalisation of our findings to benefit other SSA countries.

\section{Conclusion and policy recommendations}

In this paper, we explore questions pertaining to the persistently weak interactions in SSA among R\&I actors despite STI policy, governance and structural adjustments. We analyse the new STI policy of Rwanda (of June 2020) and that of South Africa (the 2019 White Paper on STI) and observe that they have been conceptualised on the basis of the TH and QuadH innovation approaches, respectively. In particular, we find that, while universities theoretically constitute the main and central actors in TH, the G in U-I$\mathrm{G}$ is the strongest actor with $\mathrm{U}$ remaining the weakest and most detached actor in Rwanda's NSI. While this conceptualisation of STI policies in both countries paves the way for streamlined STI governance and structural coordination, we argue that unless adequate policies are implemented to address this detached position of universities in $\mathrm{TH}$ (and NSI) and the persistently weak interactions among R\&I actors, efforts to harness the full potential of STI for development will remain largely unsuccessful in both countries.

Building on the evidence presented in the case studies for both countries we find that, in addition to weak interactions among R\&I actors and gaps in STI policy design, implementation and governance, issues relating to capacity and capabilities and structural configurations continue to contribute to the persistent weak interactions among R\&I actors. The findings suggest that gaps in STI governance responsibility and accountability and structural patterns may be obstructing R\&I interaction - for example, with respect to public funding for R\&I. In addition, we find that R\&I management capacity and capability gaps are important detrimental factors contributing to limited R\&I interactions in universities and among STI actors at large.

We conclude that it is expedient to deploy remedial strategic policy actions to address these issues. We argue that there is an urgent need to develop and implement policy instruments and strategies that will underpin and foster improved linkages and interactions among R\&I actors. Focusing to a greater extent on strengthening the capacity, capabilities and structural configurations among R\&I actors is of equally critical importance. In the context of this paper, STI policy instruments (including funding, legal and regulatory frameworks, in addition to the setting up of platforms and networks that foster collaborative project delivery among R\&I ecosystems) should seek to enable the coherence of top-down, bottom-up and horizontal R\&I approaches that nurture inclusive NSI.

As such, given the scarcity of knowledge and science/ research infrastructure (physical and virtual) in SSA, this paper is partly seeking to advance innovative approaches such as 'resource circulation' to foster R\&I actors' interactions as highlighted by the World Intellectual Property Organisation (WIPO, 2020) and Daniels et al. (2021: 232). These approaches can also help to achieve the envisaged 'network alignment' and build 'dynamic interactive capabilities', and hence to improve NSI performance. In addition, a broader consideration of innovation to include non-R\&D-performing and non-commercial actors is imperative to improve interactions and inclusion among NSI actors and stakeholders in SSA. This finding is in line with that of the OECD (2021), which calls on countries (HICs and LMICs alike) to revisit their STI frameworks, towards making them more agile and 'reorienting policy goals towards sustainability, inclusiveness and resilience ${ }^{, 6}$ (OECD, 2021: 197) for recovery and transition readiness to post-Covid-19 normalcy. 
Therefore, based on the experience of Rwanda and South Africa, we suggest five policy recommendations for African countries to strengthen existing R\&I interactions:

i. Acknowledging that in developing STI policies and strategies based on NSI and TH with a view to helping harness STI for development, it will be essential to ensure that policy frameworks (such as NSI and TH) are not deployed as static constructs but are reconceptualised in ways that take into account context-specific factors such as weaknesses among R\&I ecosystems actors, gaps in capabilities, absence of defined responsibilities and accountability mechanisms, and limitations in governance arrangements (e.g., ineffective structural configurations). Adequate attention to these factors will improve the prospects of policymaking and, especially, policy implementation.

ii. The use of NSI and TH as research and innovation policy frameworks must ensure coherence and alignment to national development priorities. Ensuring alignments between policy and development priorities in ways that inform the policy design, agenda setting, consultations, drafting and other stages of the policy processes will improve the prospects of buy-in from stakeholders, which in turn will help improve linkages among R\&I actors. Policy processes must involve a broad range of actors beyond the traditional U-I-G of TH and NSI, shifting towards comprehensive deployment of emerging policy theories and frameworks and frameworks such as 'mission-oriented innovation policy' and 'transformative innovation policy' as recommended by the OECD (2021), based on countries' specific governance and developmental aspirations. Greater inclusion of broader stakeholder groups will increase the challenge of coordination and governance, which will need to be managed. Nevertheless, this will improve the prospects for implementation.

iii. Design policy instruments such as regulatory, legal and funding frameworks that encourage and incentivise interactions among R\&I actors at individual, institutional and systems levels. For funding purposes in particular, the creation of specialised and separate funds targeting (R\&D-based and nonR\&D-based, commercial and non-commercial) research and innovation will be paramount.

iv. Strengthen the R\&I leadership and management capacity and capabilities of TH and NSI actors to enhance the governance and coordination of STI policy and programmes at micro, meso and macro levels. One way to achieve this will be by addressing the fragmentation and complexities within higher education systems, thereby enhancing interactions among R\&I actors and increasing universities' research intensity. Consolidated planning and prioritisation through formal/informal forums or networks, combined with integrated monitoring and evaluation systems will be vital.

v. Finally, reconfiguring structural arrangements in key STI agencies that embed top-down policymaking processes, while empowering bottom-up and experimental policy approaches, has the potential to improve interaction among $\mathrm{TH}$ and NSI ecosystems. This could help create and develop synergies that enable vertical and horizontal collaborations among R\&I actors in the ecosystem. This is particularly paramount at a time when countries are devising strategies for recovery and the postCovid-19 pandemic transition.

\section{Limitations and further study}

We recognise that more empirical investigations would be needed to further unpack and provide a deeper understanding of the underlying factors enabling and/or impeding actors' interactions, and the extent to which these factors affect the impact of STI on national development. Particularly, inasmuch as universities are central actors in TH systems, exploring how they interact with other actors would provide a platform to rethink not only Rwanda's and South Africa's policy and governance discourses, but also those of the wider African STI. Further and in-depth empirical research is therefore required in this regard.

\section{Declaration of conflicting interests}

The author(s) declared no potential conflicts of interest with respect to the research, authorship, and/or publication of this article.

\section{Funding}

The author(s) received no financial support for the research, authorship, and/or publication of this article.

\section{ORCID ID}

Remy Twiringiyimana (D) https://orcid.org/0000-0002-9862-8757

\section{Notes}

1. Mode 3 knowledge production is defined conceptually as a complex flow of knowledge among the academic (codified knowledge) and non-academic, including end-users (tacit knowledge), in a multi-level, multi-actor and multi-system dynamic (Baccarne et al., 2016; Carayannis and Campbell, 2009).

2. NRIF is a Rwandan public fund run by NCST while RIF is a partnership between Rwanda and the African Development Bank (AfDB) run by Angaza IM (https://www.angazacapital. com/the-rwanda-innovation-fund, accessed 7 July 2020).

3. https://www.ncst.gov.rw/content/rcc-launch (accessed 20 July 2020). 
4. In the context of South Africa, 'inclusivity' refers to considering informal sectors, the poor and marginalised communities as active participants in the innovation process, policies and outcomes (Arocena et al., 2017; Daniels et al., 2017; Kruss et al., 2012).

5. Such as the move from DST to DSI, and the bringing of STI closer to higher education.

6. According to the OECD (2021: 197), 'resilience' means the ability to recover from and adapt to disruption, and if need be, shift towards transformative paths.

\section{References}

Albuquerque E, Suzigan W, Kruss G, et al. (2015) Developing National Systems of Innovation: University-Industry Interactions in the Global South. Cheltenham: Edward Elgar Publishing.

Arocena R, Göransson B and Sutz J (2017) Developmental Universities in Inclusive Innovation Systems: Alternatives for Knowledge Democratization in the Global South, 1st edn 2018 edition. New York, NY: Palgrave Macmillan.

AU (2014) Science Technology and Innovation Strategy for Africa (STISA 2024). Available at: https://au.int/sites/ default/files/documents/38756-doc-stisa_science_tech_innova tion_strategy.pdf (accessed 25 September 2019).

AU (2019) African Innovation Outlook III | African Union. Available at: https://au.int/sites/default/files/documents/38122-docaio_3rd_edition_final_eng_repro.pdf (accessed 16 May 2020).

AUDA-NEPAD (2014) African Innovation Outlook II. Available at: https://www.nepad.org/publication/african-innovation-out look-ii (accessed 14 December 2020).

Baccarne B, Logghe S, Schuurman D, et al. (2016) Governing Quintuple Helix innovation: urban living labs and socioecological entrepreneurship. Technology Innovation Management Review 6: 22-30.

British Council (2018) Research and PhD Capacities in SubSaharan Africa: South Africa Report. International Higher Education. Available at: https://www.britishcouncil.org/sites/ default/files/h233_02_south_africa_final_web.pdf (accessed 14 December 2020).

Bush V (1945) Science: the endless frontier. Transactions of the Kansas Academy of Science (1903-) 48: 231-264.

Carayannis EG and Campbell DFJ (2009) "Mode 3" and "Quadruple Helix": toward a 21st century fractal innovation ecosystem. IJTM 46, 201. DOI: 10.1504/IJTM.2009.023374.

Cele MB, Luescher TM and Fadiji AW (2020) Innovation Policy at the Intersection: Global Debates and Local Experiences. Cape Town: HSRC Press.

Chataway J, Dobson C, Daniels C, et al. (2019) Science granting councils in Sub-Saharan Africa: trends and tensions. Science and Public Policy 46: 620-631.

Chataway J, Hanlin R and Kaplinsky R (2014) Inclusive innovation: an architecture for policy development. Innovation and Development 4: 33-54.
Crow MM and Dabars WB (2015) Designing the New American University/Michael M. Crow and William B. Dabars. Baltimore, MD: Johns Hopkins University Press.

Daniels C (2017) Science, technology, and innovation in Africa: conceptualizations, relevance, and policy directions. In: Mavhunga CC (ed) What Do Science, Technology, and Innovation Mean from Africa, pp. 169-185. Cambridge, MA: The MIT Press, ISBN 9780262533904.

Daniels C, Dosso M and Amadi-Echendu J (eds) (2021) Entrepreneurship, Technology Commercialisation, and Innovation Policy in Africa. New York, NY: Springer International Publishing.

Daniels C, Schot J, Chataway J, et al. (2020) Transformative innovation policy: insights from Colombia, Finland, Norway, South Africa and Sweden. In: Wilson Fadiji A, Cele MBG and Luescher TM (eds) Innovation Policy at the Intersection: Global Debates and Local Experiences. Cape Town: HSRC Press, p. 170.

Daniels CU, Ustyuzhantseva O and Yao W (2017) Innovation for inclusive development, public policy support and Triple Helix: perspectives from BRICS. African Journal of Science, Technology, Innovation and Development 9: 513-527.

Datta S, Saad M and Sarpong D (2019) National systems of innovation, innovation niches, and diversity in university systems. Technological Forecasting and Social Change 143: 27-36.

Diyamett B, Makundi H and Sheikheldin G (2019) Science, technology and innovation (STI) policy training for Africa: a basic module on reconciling theory, practice and policies.

Egbetokun A, Oluwadare A, Ajao B, et al. (2017) Innovation systems research: an agenda for developing countries. Journal of Open Innovation: Technology, Market, and Complexity 3: 25.

Etzkowitz H (1996) The Triple Helix: academic-industrygovernment relations. Annals of the New York Academy of Sciences 787: 67-86.

Farley SE, Rose AL, Gerard A, et al. (2013) Evaluation Report: Review of Rwanda's National Science, Technology and Innovation Policy, and Recommendations for Strategy. The Global Knowledge Initiative. Available at: http://globalknowledgeini tiative.org/wp-content/uploads/2016/10/14.08.19_DRAFT_ Rwanda-STI-Policy-Review_GKI_2014UpdateFINAL.pdf (accessed 24 December 2020).

Freeman C (1987) Technology, Policy, and Economic Performance Lessons From Japan. London: Printer Publishers. ISBN 978-0-86187-928-1.

Galvao A, Mascarenhas C, Marques C, et al. (2019) Triple Helix and its evolution: a systematic literature review. Journal of Science and Technology Policy Management 10: 812-833.

GoR (2017) National Strategy for Transformation (NST1) 2017-2024. Available at: https://www.minecofin.gov.rw/ fileadmin/user_upload/Minecofin/Publications/STRATE GIES/NST1/NST_A5_booklet_final_2.04.19_WEB.pdf (accessed 7 February 2020). 
GoR (2019a) Mission of Rwanda's Ministry of ICT and Innovation. Available at: https://minict.gov.rw/about-us/mission/ (accessed 19 April 2020).

GoR (2019b) Rwanda Education Statistics 2019. Available at: https://www.mineduc.gov.rw/fileadmin/user_upload/Mine duc/Publications/EDUCATION_STATISTICS/01_Rwanda_ Education_Statistics2019.pdf (accessed 14 December 2020).

GoR (2020a) Analysis Report 2015-2016 Rwanda National Survey of Research and Experimental Development. Available at: https://www.ncst.gov.rw/content/official-documents (accessed 7 February 2020).

GoR (2020b) Science, Technology and Innovation Policy. Available at: http://www.ncst.gov.rw/content/official-documents (accessed 7 February 2020).

GoSA (2012) National Development Plan 2030: Our Future Make It Work. Sherino Printers. Available at: https://www. gov.za/sites/default/files/gcis_document/201409/ndp-2030our-future-make-it-workr.pdf (accessed 26 April 2020).

GoSA (2016) Statistics on Post-School Education and Training in South Africa 2016. Available at: https://www.dhet.gov.za/ Research\%20Coordination\%20Monitoring\%20and\%20Evalua tion/6_DHET\%20Stats\%20Report_04\%20April\%202018.pdf (accessed 14 December 2020).

GoSA (2019) White paper on science, technology and innovation South African Government. Available at: https://www.gov.za/ documents/white-paper-science-technology-and-innovation1-mar-2019-0000 (accessed 17 April 2020).

Gouvea R., Kassicieh S and Montoya MJR (2013) Using the Quadruple Helix to design strategies for the green economy. Technological Forecasting and Social Change, World Problems, Emerging Technologies and Creative Enterprise 80: 221-230.

Hanlin R and Tigabu A (2017) Case studies of the political economy of science granting councils in sub-Saharan Africa.

Jacobs P, Habiyaremye A, Fakudze B, et al. (2019) Producing knowledge to raise rural living standards: how universities connect with resource-poor municipalities in South Africa. European Journal of Development Research 31: 881-901.

Kruss G and Visser M (2017) Putting university-industry interaction into perspective: a differentiated view from inside South African universities. Journal of Technology Transfer; Indianapolis 42: 884-908.

Kruss G, Adeoti J and Nabudere D (2012) Universities and knowledge-based development in sub-Saharan Africa: comparing university-firm interaction in Nigeria, Uganda and South Africa. The Journal of Development Studies 48: 516-530.

Lemarchand GA and Tash A (2015) UNESCO GO-SPIN Country Profiles in Science, Technology and Innovation Policy, Vol. 4; Mapping Research and Innovation in the Republic of Rwanda. Paris: UNESCO.

Lundvall B-Å (1992) National systems of innovation: towards a theory of innovation and interactive learning.

Lundvall BA (2010) National Systems of Innovation Toward a Theory of Innovation and Interactive Learning, Anthem Other Canon Economics. London: Anthem Press.
Mazzucato M (2018) Mission-oriented innovation policy: challenges and opportunities. Industrial and Corporate Change, 27(5): 803-815.

Meusburger P, Heffernan M and Suarsana L (eds) (2018) Geographies of the University, Knowledge and Space. New York, NY: Springer International Publishing.

Murenzi R and Hughes M (2006) Building a prosperous global knowledge economy in Africa: Rwanda as a case study. IJTG 2: 252 .

Nelson RR (1993) National Innovation Systems: A Comparative Analysis. Rochester, NY: Social Science Research Network.

OECD (2020) Governance in South Africa | STIP Compass. Available at: https://stip.oecd.org/stip/countries/SouthAfrica/ themes/TH1 (accessed 25 April 2020).

OECD (2021) OECD Science, Technology and Innovation Outlook 2021: Times of Crisis and Opportunity. Paris: OECD Publishing. https://doi.org/10.1787/75f79015-en.

Ranga M and Etzkowitz H (2013) Triple Helix systems: an analytical framework for innovation policy and practice in the knowledge society. Industry and Higher Education 27(4): 237-262.

Schot J and Steinmueller WE (2018) Three frames for innovation policy: R\&D, systems of innovation and transformative change. Research Policy 47: 1554-1567.

Soares MCC and Cassiolato JE (2013) Innovation systems and inclusive development: some evidence based on empirical work. Presented at the International Workshop and Journal Special Issue on New Models of Innovation for Development, University of Manchester, UK.

UNCTAD (2017) Science, technology and innovation policy review: Rwanda. Available at: https://unctad.org (accessed 17 April 2020).

UNESCO (2015) UNESCO Science Report: Towards 2030. Paris: UNESCO Publishing.

WB (2018a) Databank, Country profile, Rwanda 2018. Available at: https://databank.worldbank.org/views/reports/reportwid get.aspx?Report_Name $=$ CountryProfile $\& I d=b 450 f d 57 \&$ tbar $=\mathrm{y} \& \mathrm{dd}=\mathrm{y} \& \mathrm{inf}=\mathrm{n} \& \mathrm{zm}=\mathrm{n} \&$ country $=\mathrm{RWA}$ (accessed 14 December 2020).

WB (2018b) Databank, Country profile, South Africa 2018. Available at: https://databank.worldbank.org/views/reports/reportwid get.aspx ?Report_Name $=$ CountryProfile $\& I d=b 450 \mathrm{fd} 57 \&$ tbar $=\mathrm{y} \& \mathrm{dd}=\mathrm{y} \& \mathrm{inf}=\mathrm{n} \& \mathrm{zm}=\mathrm{n} \&$ country $=\mathrm{ZAF}($ accessed 14 December 2020).

WB (2018c) Future Drivers of Growth in Rwanda: Innovation, Integration, Agglomeration, and Competition (Vol. 2) : Overview (English). Washington, D.C.: World Bank Group. Available at: http://documents.worldbank.org/curated/en/ 680671541618477651/Overview (accessed 19 April 2020).

WIPO (2020) Global Innovation Index 2020: Who Will Finance Innovation? Available at: https://www.wipo.int/edocs/pub docs/en/wipo_pub_gii_2020.pdf (accessed 24 February 2021).

Yongabo P (2021) Research and innovation uptake landscape in Rwanda: analysis of the STI framework. In: Daniels C, Dosso M and Amadi-Echendu J (eds) Entrepreneurship, 
Technology Commercialisation, and Innovation Policy in Africa. Cham: Springer International Publishing, pp. 217-235.

Yongabo P and Göransson B (2020) Constructing the national innovation system in Rwanda: efforts and challenges.
Innovation and Development. DOI: 10.1080/2157930X.2020. 1846886.

Zavale NC and Langa PV (2018) University-industry linkages' literature on Sub-Saharan Africa: systematic literature review and bibliometric account. Scientometrics 116:1-49. 